\title{
Treatment Strategies in 135 Consecutive Patients with Enterocutaneous Fistulas
}

\author{
Ruben G. J. Visschers · Steven W. M. Olde Damink • \\ Bjorn Winkens · Peter B. Soeters · Wim G. van Gemert
}

Published online: 4 January 2008

(C) The Author(s) 2007

\begin{abstract}
Background Enterocutaneous fistulas (ECF) pose a major challenge to every gastrointestinal (GI) surgeon. Based on earlier studies, a standardized treatment guideline was implemented. The focus of the present study was to assess that guideline and determine prognostic factors for outcome of patients with ECF, and to define a more detailed therapeutic approach including the convalescence time before restorative surgery.

Methods All patients with ECF treated between 1990 and 2005 were included. Management consisted of controlling Sepsis, Optimization of nutritional state, Wound care, assessment of fistula Anatomy, Timing of surgery, and Surgical strategy (the SOWATS guideline). Prognostic factors were assessed by way of multiple logistic regression analysis.

Results A total of 135 patients were treated at our unit. Overall closure was achieved in 118 patients (87.4\%). Restorative operations for fistula closure were performed after a median of 53 days (range: 4-270 days). Restorative operations were successful in 97/107 patients (90.7\%). Thirteen patients $(9.6 \%)$ died. An abdominal wall defect was the most predominant negative prognostic factor for
\end{abstract}

R. G. J. Visschers · S. W. M. Olde Damink ·

P. B. Soeters · W. G. van Gemert $(\square)$

Department of Surgery, Intestinal Failure Institute Maastricht and Nutrition \& Toxicology Research Institute Maastricht (NUTRIM), University Hospital Maastricht, Maastricht, The Netherlands

e-mail: w.vangemert@ah.unimaas.nl

B. Winkens - W. G. van Gemert

Department of Methodology and Statistics, Maastricht University, PO Box 5800, 6202, AZ, Maastricht, The Netherlands spontaneous closure (odds ratio $[\mathrm{OR}]=0.195$, confidence interval $[\mathrm{CI}] 0.052-0.726, p=0.015)$. A strong relation was found between preoperative albumin level and surgical closure $(p<0.001)$ and mortality $(p<0.001)$.

Conclusions Application of the SOWATS guideline allowed a favorable outcome after a short convalescence period. Abdominal wall defects and preoperative hypoalbuminemia are important prognostic variables.

The treatment of patients with enterocutaneous fistulas (ECF) is complex and a challenge to every gastrointestinal (GI) surgeon. Since the first major report in 1960 [1], reporting a mortality rate of $44 \%$, much energy has been invested in optimizing the treatment of patients with ECF. In the second half of the last century, mortality decreased to 5\%-25\% [2-5] because of improved surgical, metabolic, and medical care. At present, the treatment of patients with an abdominal wall defect in which a fistula develops in the exposed intestine is probably the biggest challenge [6]. The few retrospective studies available in the literature concerning these patients are either incomplete or only describe small series of patients [7-12] (Tables 1, 2, 3).

Overall, the incidence of ECF is low. Consequently, randomized studies are lacking and management principles are based on expert opinion. There is no evidence-based grade A recommendation on how these patients should be treated, but a few paradigms exist: spontaneous closure is less common in fistulas caused by malignancy or Crohn's disease $[13,14]$ but is predominantly seen in colonic ECF, in low-output fistulas [14-17], and in patients with a closed abdomen [7, 18]. There is consensus that treatment of sepsis and restoring nutritional state are priorities. Moreover, it is generally recommended that patients not undergo 
Table 1 Overview of the literature. Overall results

${ }^{\text {a }}$ Gastrointestinal fistulas

b Entercoutaneous fistulas

c Small bowel fistulas

Table 2 Overview of literature. Results of fistulas within a closed abdominal wall

a Gastrointestinal fistulas

b Entercoutaneous fistulas

c Small bowel fistulas

d Success rate is $72 \%$

Table 3 Overview of literature. Results of fistulas with an abdominal wall defect

${ }^{\text {a }}$ Gastrointestinal fistulas

b Entercoutaneous fistulas

c Small bowel fistulas

d Success rate is $47 \%$

NA not available

\begin{tabular}{lllll}
\hline Author & $\begin{array}{l}\text { Number of } \\
\text { patients }\end{array}$ & $\begin{array}{l}\text { Surgical } \\
\text { closure, \% }\end{array}$ & $\begin{array}{l}\text { Spontaneous } \\
\text { closure, \% }\end{array}$ & $\begin{array}{l}\text { Overall } \\
\text { mortality, \% }\end{array}$ \\
\hline Sitges-Serra et al. [7] $^{\mathrm{a}}$ & 75 & 13.3 & 65.3 & 21.3 \\
Conter et al. [8] $^{\mathrm{b}}$ & 51 & 80.4 & 9.8 & 7.8 \\
Levy et al. [9] $^{\mathrm{c}}$ & 335 & 37.3 & 29 & 33.7 \\
Schein and Decker [10] $^{\mathrm{a}}$ & 117 & $\mathrm{NA}$ & $\mathrm{NA}$ & 37 \\
Chamberlain et al. [11] $^{\mathrm{c}}$ & 25 & 24 & 32 & 40 \\
Hollington et al. [12] $^{\mathrm{a}}$ & 277 & 43.7 & 25.6 & 15.2 \\
Present study $^{\mathrm{b}}$ & 135 & 71.9 & 15.6 & 9.7 \\
\hline
\end{tabular}

\begin{tabular}{lllll}
\hline Author & $\begin{array}{l}\text { Number of } \\
\text { patients }\end{array}$ & $\begin{array}{l}\text { Surgical } \\
\text { closure, } \%\end{array}$ & $\begin{array}{l}\text { Spontaneous } \\
\text { closure, \% }\end{array}$ & $\begin{array}{l}\text { Overall } \\
\text { mortality, \% }\end{array}$ \\
\hline Sitges-Serra et al [7] $^{\mathrm{a}}$ & 65 & 10.8 & 73.8 & 15.4 \\
Conter et al. [8] $^{\mathrm{b}}$ & 36 & NA & 13.9 & NA \\
Levy et al. [9] $^{\mathrm{c}}$ & 170 & NA & NA & 23 \\
Schein and Decker [10] $^{\mathrm{a}}$ & 72 & NA & NA & 22.2 \\
Chamberlain et al. [11] $^{\mathrm{c}}$ & 22 & 27.3 & 36.4 & 31.8 \\
Hollington et al. [12] $^{\mathrm{a}}$ & 245 & NA & NA & $14.6^{\mathrm{d}}$ \\
Present study $^{\mathrm{b}}$ & 82 & 68.3 & 22 & 6.1 \\
\hline
\end{tabular}

\begin{tabular}{lllll}
\hline Author & $\begin{array}{l}\text { Number of } \\
\text { patients }\end{array}$ & $\begin{array}{l}\text { Surgical } \\
\text { closure, } \%\end{array}$ & $\begin{array}{l}\text { Spontaneous } \\
\text { closure, \% }\end{array}$ & $\begin{array}{l}\text { Overall } \\
\text { mortality, \% }\end{array}$ \\
\hline Sitges-Serra et al. [7] $^{\mathrm{a}}$ & 10 & 30 & 10 & 60 \\
Conter et al. [8] $^{\mathrm{b}}$ & 15 & $\mathrm{NA}$ & 0 & NA \\
Levy et al. [9] $^{\mathrm{c}}$ & 165 & $\mathrm{NA}$ & $\mathrm{NA}$ & 44 \\
Schein and Decker [10] $^{\mathrm{a}}$ & 45 & $\mathrm{NA}$ & $\mathrm{NA}$ & 60 \\
Chamberlain et al. [11] $^{\mathrm{c}}$ & 3 & 0 & 0 & 100 \\
Hollington et al. [12] $^{\mathrm{a}}$ & 32 & NA & NA & $18.8^{\mathrm{d}}$ \\
Present study $^{\mathrm{b}}$ & 53 & 77.3 & 5.7 & 15.1 \\
\hline
\end{tabular}

restorative surgery within 3-6 months after ECF development [17, 19, 20].

In our unit, treatment of patients with ECF is standardized and based on the outcome of a large retrospective study [2] and a study of patients treated in our unit according to a standardized guideline [21]. Since this last study, high-resolution computerized tomography (CT) has become available, allowing precise drainage procedures of abscesses by intervention radiology or local surgical drainage [22, 23] instead of complete re-laparotomy. In addition, materials have become available, such as absorbable vicryl mesh, for temporary abdominal wall closure. Moreover, we have changed to a more defensive surgical technique. We have titrated the timing of restorative surgery to individual patient conditions, as opposed to a pre-planned time interval of 3-6 months between fistula occurrence and restorative surgery. Since 1990, all patients with ECF admitted to our hospital have been treated according to this renewed guideline.
The goal of the present study was to audit the results of this approach in patients with complex ECF and to identify the time of convalescence prior to restorative surgery. Our secondary aim was to identify prognostic factors for fistula closure and mortality in these patients. More specifically, we wanted to test if spontaneous closure was related to the cause, output, and location of the ECF and the presence of an abdominal wall defect.

\section{Patients and methods}

\section{Patients}

In this retrospective analysis, a database was created consisting of 135 patients with ECF consecutively treated at our unit between 1990 and 2005. Since 1990, all patients have been treated according to the SOWATS guideline (see Methods, below). Patients with gastroduodenal, pancreatic, 
biliary, and perianal fistulas were excluded. Patients who displayed intestinal anastomotic leakage soon after the primary surgical procedure and immediately underwent relaparotomy were not defined as having an ECF. However, when no re-laparotomy was performed and patients developed an ECF, they were treated according to the guideline. Information was gathered from the nutrition team database and from patient files.

An ECF was considered to be closed when there was no communication between the intestine and the abdominal wall, and no signs of inflammation. Subsequently, recurrence was defined as a renewed connection between the intestine and skin after the fistula either had been surgically removed or had spontaneously closed. Abdominal wall defect is defined as any defect of all layers of the abdominal wall leaving the abdominal contents exposed.

\section{Methods}

The SOWATS treatment guideline consists of the following components: Sepsis, Optimization of nutritional state, Wound care, Anatomy (of the fistula), Timing of surgery, and Surgical strategy. It is roughly similar to the treatment approach advocated in earlier reports $[2,12,17,19,21,24-$ 26]. Each of the components of the protocol is described below:

- Sepsis. Control of sepsis has the highest priority. The suspicion of a septic focus is based on one or more clinical signs: fever, failure to respond to nutrition, and jaundice, accompanied with increased infection parameters, decreased plasma albumin levels, positive fluid balance, development of edema, and organ failure. These signs are sometimes different and blunted when patients are clinically depleted, which is often the case in ECF patients. When clinical signs indicate the presence of a septic focus, enteral and intravenous contrast-enhanced CT is used to identify and outline abscesses and to guide percutaneous drainage or local surgical drainage procedures. Complete re-laparotomy is avoided between 1 and 6 weeks after the initial surgery or the occurrence of the ECF. At this stage, dissection is difficult and likely to cause damage to the abdominal contents [27].

- Optimization of nutritional state. Nutritional management is always preceded by rehydration and electrolyte correction. Within 24-48 h after the appearance of (a) small bowel fistula(s) parenteral nutrition is initiated and includes the administration of trace elements and vitamins. Enteral nutrition is considered in cases of small bowel fistulas not expected to close spontaneously, in large bowel fistulas, and when fistula output does not interfere with wound care. Patients are always allowed to ingest clear fluids up to $500 \mathrm{ml} /$ day.

- Wound care: Specialist wound care is applied to prevent maceration and excoriation of the skin by intestinal fluid leakage from the fistula, precluding proper healing after the restorative operation and abdominal wall reconstruction in a later stage operation. Fluids are collected in a wound manager and drained through sump-suction, which also allows output measurement.

- Anatomy. The anatomy of the fistula is defined prior to planned surgery. Contrast studies are performed in which water-soluble contrast material is administered through the fistula, orally, and rectally. The complete bowel tract is visualized so that the surgeon can be informed about the fistula anatomy, the length of the proximal bowel, and the quality of the remaining bowel (obstruction/stenosis).

- Timing of surgery. Patients are eligible for surgery when septic foci are adequately treated and subjective criteria for a good clinical and nutritional condition are met. These criteria include the patient's becoming mobile, feeling well, taking an interest in his/her surroundings, and becoming impatient to proceed with the restorative surgery. The absence of signs of sepsis is defined by increasing albumin and hemoglobin and decreasing leukocyte and thrombocyte counts, C-reactive protein and erythrocyte sedimentation rate levels. The minimal period between the development of the fistula and the restorative surgical approach is 6 weeks.

- Surgical strategy. There are some distinct surgical principles to be reckoned with: Complete dissection of the bowel tract is necessary to ensure unhindered passage and to allow mobilization of the abdominal wall and thereby facilitate closure at the end of the operation. The number of anastomoses is limited to a minimum, and each one must be covered with healthy tissue and positioned away from other sutures lines. Use of a non-absorbable mesh is avoided to reduce the possibility of infection and recurrence of fistulas. In some cases a proximal double-barrelled small bowel enterostomy is constructed to protect more distal anastomoses that are at risk of leakage. These enterostomies are placed in such a manner that later closure is possible through local small incisions.

Statistical analysis

Univariate analysis was performed using Pearson's chisquare test and Fisher's exact test where appropriate. Independent variables affecting ECF closure included age 
(younger or older than 60 years), sex, patient origin (University Hospital Maastricht (azM) or other), primary disease (inflammatory bowel disease, malignancy or a miscellaneous group consisting of appendicitis, diverticulitis, ileus, several nonmalignant processes, and vascular diseases, among others), cause (postsurgical or spontaneous), anatomy (small or large bowel), output $(<500$ or $\geq$ $500 \mathrm{ml} /$ day), abdominal wall status (open or closed), sepsis (yes or no), only total parenteral nutrition (TPN: yes or no), recurrence of fistula (yes or no), and albumin level before restorative surgery $(<25$ or $\geq 25 \mathrm{~g} / \mathrm{l})$. Outcome variables included spontaneous closure, surgical closure, and death. The patient was the unit of analysis, and all independent variables with a two-tailed $p<0.10$ were included into a multiple logistic regression model. The final model was reduced by the backward elimination method based on the likelihood ratio test. Two-tailed $p<0.05$ were considered significant. Statistical analyses were performed with SPSS software (version 13; SPSS Inc., Chicago, IL, USA).

\section{Results}

\section{Patient characteristics}

Data from 135 patients experiencing 163 episodes of ECF were analyzed (Table 4). Mean age was 57 years (range: 16-87 years). Postoperative fistulas after initial surgery appeared after a median of 21 days (range: 1-494 days). The median length of hospital stay was 56 days (range: 6-317 days). However, because several patients received treatment including TPN at home, the median period of treatment was 70 days (range: 6-497 days). Intensive care treatment and artificial ventilation were necessary for 33 patients during $50 \mathrm{ICU}$ admissions, lasting a median of 8.5 days (range: 1-171 days).

Treatment of infectious complications and nutritional management

Most patients referred to our hospital had suffered a septic episode in the referring hospital. A total of 73 patients experienced one or more septic episodes in our department. In this latter group 15 patients had radiological signs of small or very superficial collections and were treated with antibiotics only. Computerized tomography-guided drainage of abscesses was necessary in 28 patients, none of whom required further intervention. A drainage procedure was attempted in three patients but was technically impossible. Five patients underwent drainage through local incisions, and one of those patients eventually required a re-laparotomy. Re-laparotomy was performed as a first choice in six patients because of fecal peritonitis, abdominal compartment syndrome, and the presence of multiple abscesses. Additionally, 10 patients had a CT without proof of an abdominal focus for sepsis. Most often, the primary source of infection in these patients was the central venous line and to a lesser extent, the urinary tract and the lungs. Six patients with sepsis did not receive a CT but were immediately diagnosed with a central venous line infection. In total, central venous line infections were seen in 25 patients. One patient died from catheter-related sepsis. Overall, sepsis could not be controlled in 10 patients, all of whom later died.

Total parenteral nutrition alone was administered to 82 patients for a median of 44 days (range: 3-219 days). Twenty patients received enteral nutrition in combination with parenteral feeding, and 33 patients received total enteral nutrition without compromising wound care.

\section{Patient outcome}

Fistula closure was accomplished in 118 patients, giving an overall success rate of $87.4 \%$. Spontaneous closure occurred in 21 patients $(15.6 \%)$ and surgical closure was achieved in 97 patients $(71.9 \%$ ) (Table 5). The median time between fistula development and spontaneous closure was 18 days (range: 7-49 days). Surgical intervention was performed after a median period of 53 days (range: 4270 days) from occurrence of the fistula. The overall success of surgical treatment was $90.7 \%$, and the overall mortality rate was $9.6 \%$ (13 patients). Of the 13 patients who died, 3 died of non-fistula- related causes: cancer (2) and myocardial infarction (1). Sepsis was the cause of death in the remaining 10 patients, resulting in a fistularelated mortality of $7.4 \%$. Four patients died before undergoing restorative surgery, and four others did not finish treatment at our department but were transferred to other hospitals or institutions (Fig. 1). In only one of these patients was a decision made to refrain from restorative surgery because of progressive malignancy.

\section{Abdominal wall}

An abdominal wall defect was present in 53 patients (Tables 4 and 5). Causes for the abdominal wall defects included (1) spontaneous dehiscence after surgery, resulting from bowel distension and adynamic ileus; (2) infectious complications, or (3) intentional opening of the abdominal wall in case of increased intra-abdominal pressure leading to cardiovascular instability. Closure of the fistula was accomplished in 44 patients (83.0\%). Spontaneous closure was seen in only 3 of these patients $(5.7 \%)$, 
Table 4 Patient characteristics of the total population and of patients with an open abdominal wall

\begin{tabular}{|c|c|c|c|c|c|c|c|c|c|}
\hline \multirow{2}{*}{\multicolumn{5}{|c|}{ with an open abdominal wall }} & \multirow{2}{*}{\multicolumn{3}{|c|}{ Total population }} & \multirow{2}{*}{\multicolumn{2}{|c|}{ Open abdomen }} \\
\hline & & & & & & & & & \\
\hline & Tota & pulation & Op & domen & \multirow{2}{*}{$\begin{array}{l}<25 \\
\geq 25\end{array}$} & \multirow{2}{*}{$\begin{array}{l}25 \\
62\end{array}$} & \multirow{2}{*}{$\begin{array}{l}24.3^{\mathrm{a}} \\
60.2^{\mathrm{a}}\end{array}$} & \multirow{2}{*}{$\begin{array}{l}14 \\
24\end{array}$} & \multirow{2}{*}{$\begin{array}{l}28.6^{\mathrm{b}} \\
49.0^{\mathrm{b}}\end{array}$} \\
\hline Variable & $\mathrm{N}$ & $\%$ & $\mathrm{~N}$ & $\%$ & & & & & \\
\hline Patients & 135 & 100 & 53 & 100 & \multirow{2}{*}{\multicolumn{5}{|c|}{$\begin{array}{l}{ }^{a} \text { Percentage of total number initial surgical restorative procedures } \\
(103)\end{array}$}} \\
\hline Number of fistulas & 163 & NA & 60 & NA & & & & & \\
\hline Age (years) & & & & & \multicolumn{5}{|c|}{$\begin{array}{l}\mathrm{b} \text { Percentage of total number initial surgical restorative procedures } \\
\text { (49) }\end{array}$} \\
\hline$<60$ & 67 & 49.6 & 22 & 41.5 & \multirow{2}{*}{\multicolumn{5}{|c|}{$\begin{array}{l}\text { azM University Hospital Maastrict; IBD inflammatory bowel disease; } \\
\text { TPN total parenteral nutrition }\end{array}$}} \\
\hline$\geq 60$ & 68 & 50.4 & 31 & 58.5 & & & & & \\
\hline
\end{tabular}

Sex

$\begin{array}{lllll}\text { Male } & 65 & 48.1 & 31 & 58.5 \\ \text { Female } & 70 & 51.9 & 22 & 41.5\end{array}$

Patient origin

$\begin{array}{lllll}\text { azM surgical department } & 82 & 60.7 & 30 & 56.6 \\ \text { Other } & 53 & 39.3 & 23 & 43.4\end{array}$

Primary disease

Miscellaneous

IBD

Malignancy

Cause of fistula

Surgical

Spontaneous

119

16

88.1

11.9

51

96.2

Anatomy of fistula

Small bowel

Large bowel

104

77.0

47

88.7

26

19.3

Output (ml/day)

$$
<500
$$

$\geq 500$

Abdominal wall

\section{Open}

Closed

NA

Sepsis

$$
\text { Yes }
$$

No

Only TPN

$$
\text { Yes }
$$

No

60.7

39.3

$$
33
$$

62.3

53

Recurrence

$\begin{array}{lllll}\text { Yes } & 18 & 13.3 & 9 & 17.0 \\ \text { No } & 117 & 86.7 & 44 & 83.0\end{array}$

Preoperative albumin (g/l)
Table 4 continued

closure through restorative surgery was achieved in 41 patients $(77.3 \%)$. Because a total of 49 patients underwent restorative surgery, the surgical success rate within this group was $83.7 \%$. Eight patients $(15.1 \%$ ) died of sepsis, all following restorative surgery. One patient was transferred to another hospital with an open fistula. All patients who were treated successfully left the hospital with a closed abdomen, and at least a quarter of these patients later required correction of a newly developed abdominal wall hernia.

\section{Spontaneous closure}

Several variables were significantly related to spontaneous closure, surgical closure, and mortality (Table 6). Spontaneous closure predominantly occurred in patients with an intact abdominal wall $(p=0.014)$, and in patients who received TPN $(p=0.014)$. Multiple logistic regression analysis showed that abdominal wall status and TPN administration were independent predictors for spontaneous closure. The odds ratios for open versus closed abdominal wall and for TPN administration versus no TPN were 0.195 (CI $0.052-0.726 ; p=0.015$ ) and 5.466 (CI $1.464-20.410 ; p=0.012$ ), respectively. Patient origin was retained in this model because of near significance $(\mathrm{OR}=$ 3.310 CI $0.994-11.109 ; p=0.051$ ).

\section{Surgical closure and mortality}

Surgical closure was negatively associated with male sex $(p=0.043)$, high output $(p=0.030)$, abdominal wall defect $(p=0.041)$, presence of sepsis $(p=0.017)$, fistula recurrence $(p=0.012)$, and a preoperative albumin level below $25 \mathrm{~g} / \mathrm{l}(p<0.001)$. Mortality was higher in patients older than 60 years $(p=0.002)$, of male sex $(p=0.040)$, with high-output fistulas $(p=0.031)$, sepsis $(p=0.006)$, and a preoperative albumin level below $25 \mathrm{~g} / \mathrm{l}(p<0.001)$ (Table 6). 
Table 5 Outcome of treatment in the total population and specified for abdominal wall status

\begin{tabular}{|c|c|c|c|c|c|c|}
\hline & \multicolumn{2}{|c|}{ Total population $(n=135)$} & \multicolumn{2}{|c|}{ Open abdomen $(n=53)$} & \multicolumn{2}{|c|}{ Closed abdomen $(n=82)$} \\
\hline & Number & $\%$ & Number & $\%$ & Number & $\%$ \\
\hline Closure & 118 & 87.4 & 44 & 83.0 & 74 & 90.2 \\
\hline Spontaneous & 21 & 15.6 & 3 & 5.7 & 18 & 22.0 \\
\hline Surgical & 97 & 71.9 & 41 & 77.4 & 56 & 68.3 \\
\hline Success of surgery & $97 / 107$ & 90.7 & $41 / 49$ & 83.7 & $56 / 58$ & 96.6 \\
\hline Mortality & 13 & 9.7 & 8 & 15.1 & 5 & 6.1 \\
\hline Persisting fistula & 4 & 3.0 & 1 & 1.9 & 3 & 3.7 \\
\hline
\end{tabular}

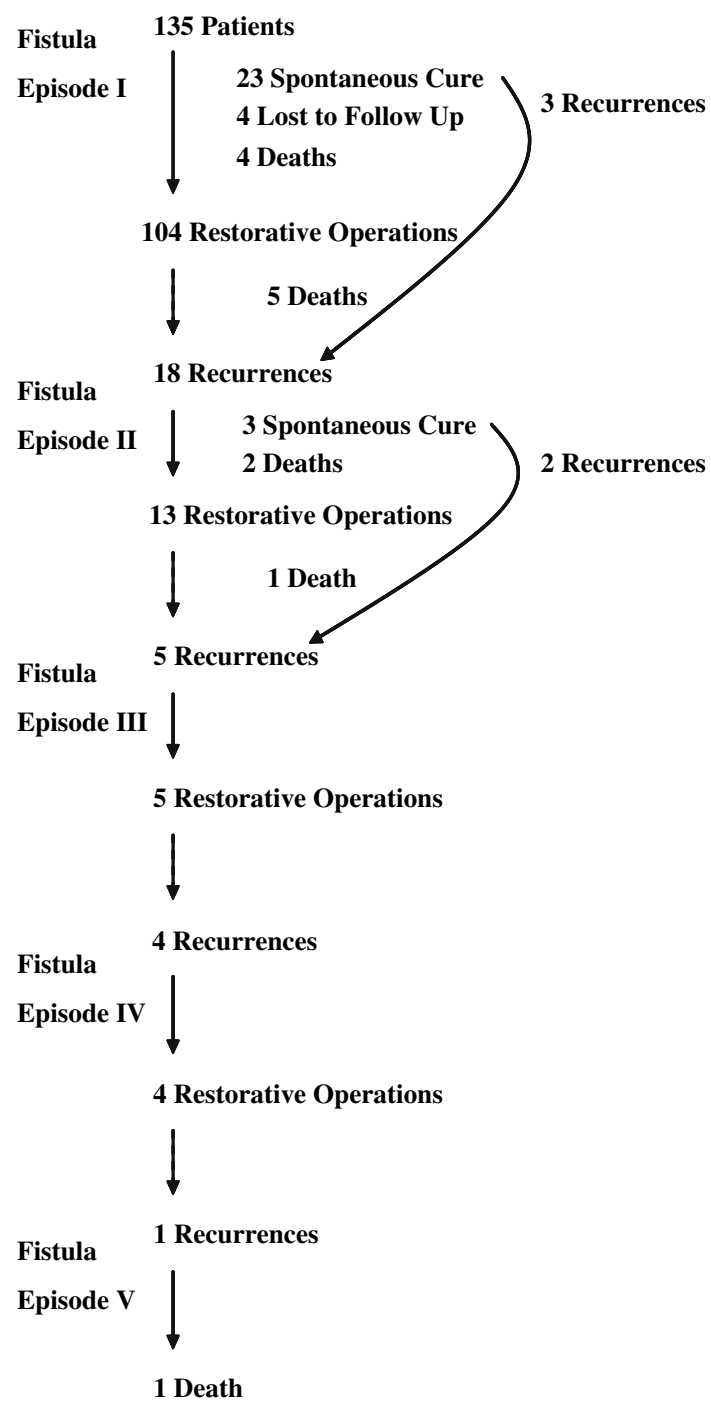

Fig. 1 Flow chart of patient outcome

A strong relation was observed between preoperative albumin levels and mortality (Table 6, Fig. 2), making multiple logistic regression analysis impossible. Likewise, success of surgery is strongly dependent on the preoperative albumin level. All 62 patients with a preoperative albumin level above $25 \mathrm{~g} / \mathrm{l}$ survived with a healed fistula.
Eight of 25 patients with a preoperative albumin level below $25 \mathrm{~g} / \mathrm{l}$ died (32\%). The preoperative albumin level was unknown in 20 patients, 1 of whom died. A subgroup analysis of all 25 patients with an albumin level below $25 \mathrm{~g} / \mathrm{l}$ showed that abdominal wall defect was the only variable significantly associated with mortality $(p=0.030)$. Six of 12 patients $(50 \%)$ with an abdominal wall defect died, compared to 2 out of $13(15 \%)$ patients with a closed abdominal wall.

\section{Discussion}

The present study shows that adherence to a treatment guideline for patients with ECF results in good general outcome despite a relatively short period of convalescence. The restorative operation was performed after a median interval of 53 days, without compromising outcome, as shown by a high success rate and low mortality. Timing of surgery was titrated on the basis of day-to-day patient characteristics instead of observing a fixed time period (3-6 months) between fistula occurrence and restorative surgery $[17,19,20]$.

Spontaneous closure of ECF did not occur after 7 weeks. In our series, spontaneous closure was limited to patients in whom fistulas developed after primary surgery in our own hospital. This patient bias is not surprising, because ECF that tend to close spontaneously are unlikely to be referred. A bias also occurs when considering the effect of TPN. Because patients are given TPN and nil by mouth when the ECF is already expected to close spontaneously, the multiple logistic regression analysis will be influenced. Therefore we cannot conclude that bowel rest facilitated by TPN promotes spontaneous closure. In proximal high-output fistulas, TPN is required to allow administration of full nutritional requirements and to simplify wound care by decreasing fistula output [13, 28].

Interestingly, other variables used clinically in earlier reports to judge the likelihood of spontaneous closure [1417] were not convincingly confirmed in our study. Spontaneous closure of ECF was not influenced by anatomy 
Table 6 Univariate analysis of outcome

\begin{tabular}{|c|c|c|c|c|c|c|}
\hline \multirow[b]{2}{*}{ Variable } & \multicolumn{2}{|c|}{ Spontaneous closure } & \multicolumn{2}{|c|}{ Surgical closure } & \multicolumn{2}{|c|}{ Mortality } \\
\hline & Ratio & $p$ Value & Ratio & $p$ Value & Ratio & $p$ Value \\
\hline Age (years) & & 0.486 & & 0.093 & & 0.002 \\
\hline$<60$ & $12 / 67$ & & $51 / 53$ & & $1 / 67$ & \\
\hline$\geq 60$ & $9 / 68$ & & $46 / 54$ & & $12 / 68$ & \\
\hline Sex & & 1.000 & & $0.043^{*}$ & & 0.040 \\
\hline Male & $10 / 65$ & & $42 / 50$ & & $10 / 65$ & \\
\hline Female & $11 / 70$ & & $55 / 57$ & & $3 / 70$ & \\
\hline Patient origin & & 0.051 & & $0.746^{\mathrm{a}}$ & & 0.766 \\
\hline azM surgical department & $17 / 82$ & & $55 / 60$ & & $7 / 82$ & \\
\hline Other & $4 / 53$ & & $42 / 47$ & & $6 / 53$ & \\
\hline Primary disease & & $0.675^{\mathrm{a}}$ & & $0.722^{\mathrm{a}}$ & & $0.294^{\mathrm{a}}$ \\
\hline Miscellaneous & $11 / 81$ & & $60 / 65$ & & $7 / 81$ & \\
\hline IBD & $4 / 24$ & & $19 / 21$ & & $1 / 24$ & \\
\hline Malignancy & $6 / 30$ & & $18 / 21$ & & $5 / 30$ & \\
\hline Cause of fistula & & $1.000^{\mathrm{a}}$ & & $0.353^{\mathrm{a}}$ & & $0.364^{\mathrm{a}}$ \\
\hline Surgical & $19 / 119$ & & $83 / 93$ & & $13 / 119$ & \\
\hline Spontaneous & $2 / 16$ & & $14 / 14$ & & $0 / 16$ & \\
\hline Anatomy of fistula & & $0.763^{\mathrm{a}}$ & & $1.000^{\mathrm{a}}$ & & $1.000^{*}$ \\
\hline Small bowel & $17 / 104$ & & $75 / 83$ & & $10 / 104$ & \\
\hline Large bowel & $3 / 26$ & & $20 / 22$ & & $2 / 26$ & \\
\hline Output & & 0.811 & & $0.030^{\mathrm{a}}$ & & 0.031 \\
\hline \multicolumn{7}{|l|}{ (ml/day) } \\
\hline$<500$ & $9 / 56$ & & $43 / 44$ & & $2 / 56$ & \\
\hline$\geq 500$ & $11 / 61$ & & $38 / 46$ & & $10 / 61$ & \\
\hline Abdominal wall & & 0.014 & & $0.041^{\mathrm{a}}$ & & 0.133 \\
\hline Open & $3 / 53$ & & $41 / 49$ & & $8 / 53$ & \\
\hline Closed & $18 / 82$ & & $56 / 58$ & & $5 / 82$ & \\
\hline Sepsis & & 1.000 & & $0.017^{\mathrm{a}}$ & & 0.006 \\
\hline Yes & $11 / 73$ & & $47 / 56$ & & $12 / 73$ & \\
\hline No & $10 / 62$ & & $50 / 51$ & & $1 / 62$ & \\
\hline Only TPN & & 0.014 & & $1.000^{\mathrm{a}}$ & & 1.000 \\
\hline Yes & $18 / 82$ & & $53 / 59$ & & $8 / 82$ & \\
\hline No & $3 / 53$ & & $44 / 48$ & & $5 / 53$ & \\
\hline Recurrence & & $0.306^{\mathrm{a}}$ & & $0.012^{\mathrm{a}}$ & & $0.073^{\mathrm{a}}$ \\
\hline Yes & $1 / 18$ & & $13 / 18$ & & $4 / 18$ & \\
\hline No & $20 / 117$ & & $84 / 89$ & & $9 / 117$ & \\
\hline Preoperative & & NA & & $0.000^{\mathrm{a}}$ & & $0.000^{\mathrm{a}}$ \\
\hline \multicolumn{7}{|l|}{ Albumin (g/l) } \\
\hline$<25$ & NA & & $17 / 25$ & & $8 / 25$ & \\
\hline$\geq 25$ & NA & & $61 / 62$ & & $0 / 62$ & \\
\hline
\end{tabular}

${ }^{\text {a }}$ Fisher's exact test

(e.g., large or small bowel), by output, or by cause of the ECF. However, an ECF within an abdominal wall defect and not adjacent to viable skin is unlikely to close spontaneously.

This study shows that hypoalbuminemic patients fail to recover well after restorative surgery. Albumin levels therefore provide, in addition to clinical signs, a good measure to assess a patient's health status [29-31], and surgical intervention will ideally be performed when levels are normal. Like other acute phase proteins [32], albumin as an indicator of inflammatory activity is a potent indicator of surgical risk [31]. It is well known that 


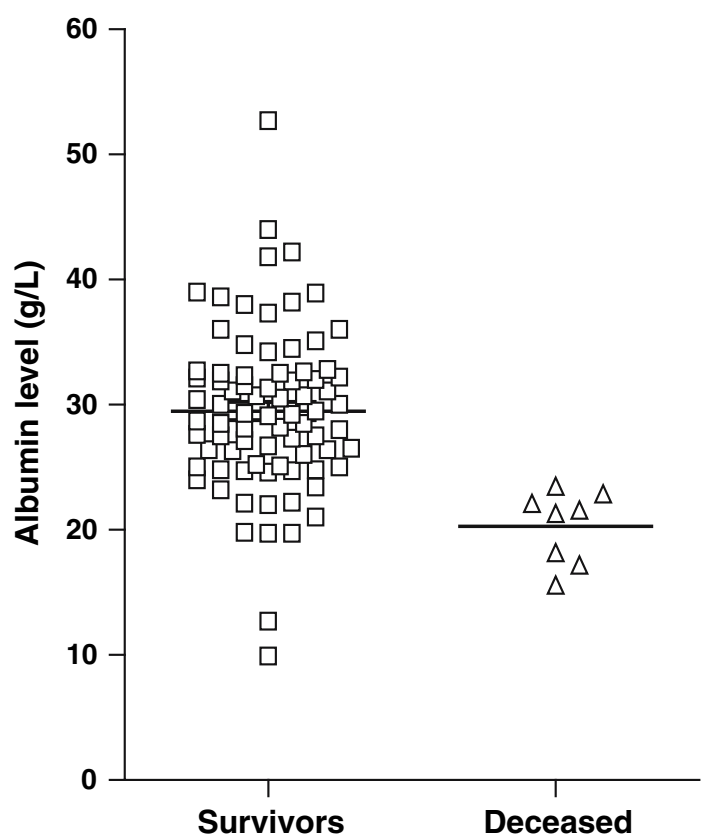

Fig. 2 Scatter plot of preoperative albumin level related to patient outcome ( $t$-test for unpaired samples $p<0.001$ )

inflammatory activity diminishes the ability of the patient to respond well to a second hit [19]. In this study, 25 patients with an albumin level below $25 \mathrm{~g} / \mathrm{l}$ underwent operation. These patients represented a seriously ill group that continued to show signs of inflammation despite all endeavors to treat infection and in which postponement of surgery was thought to lead to further deterioration.

The relatively low overall mortality rate of $10 \%$ in the present study compares favorably with rates reported in the literature (Tables 1-3). This is especially encouraging because the current population consisted of a greater proportion of patients with an abdominal wall defect, which increased from around 20\% (reference data not reported in our publications) to $39 \%$ in the present series, and had more co-morbidity compared to our previous studies $[2$, 27]. This improvement may be caused by more effective and more rapid tackling of sepsis or as a result of improved intensive care monitoring and treatment of septic foci by CT-guided drainage or via small surgical incisions.

Mortality is related to sepsis, age, sex, and fistula output. Multi-organ failure caused by sepsis is still the main cause of death in spite of advanced medical treatment. Although treatment of complications should be optimized, it is also important to prevent complications by improving the condition of the patient before operation, but also to adapt the extent of the surgical trauma to the patient's ability to adequately respond to that trauma. The increased risk of postoperative sepsis in the elderly has also been demonstrated by other investigators [33].
The main lesson to be learned from this study is that adherence to a standardized guideline can result in good patient outcome. Phased treatment is proposed, with the initial emphasis on the treatment of septic foci, aiming to improve the patient's condition. Surgical repair is performed when the patient is stable [34, 35]. After a recovery period of at least 6 weeks, a one-stage treatment can be performed successfully in most cases. Spontaneous closure in the present series did not depend on output or anatomy, whereas abdominal wall defect was a negative predictor. Treatment of sepsis plays a key role and ongoing sepsis is still the most important cause of death.

Acknowledgments This work was supported by a grant from the Netherlands Organisation for Health Research and Development to Steven W. M. Olde Damink (Klinische Fellow, grant nr 40-00703-9706-177).

Open Access This article is distributed under the terms of the Creative Commons Attribution Noncommercial License which permits any noncommercial use, distribution, and reproduction in any medium, provided the original author(s) and source are credited.

\section{References}

1. Edmunds LH Jr, Williams GM, Welch CE (1960) External fistulas arising from the gastrointestinal tract. Ann Surg 152:445471

2. Soeters PB, Ebeid AM, Fischer JE (1979) Review of 404 patients with gastrointestinal fistulas. Impact of parenteral nutrition. Ann Surg 190:189-202

3. McIntyre PB, Ritchie JK, Hawley PR et al. (1984) Management of enterocutaneous fistulas: a review of 132 cases. Br J Surg 71:293-296

4. Campos AC, Andrade DF, Campos GM et al. (1999) A multivariate model to determine prognostic factors in gastrointestinal fistulas. J Am Coll Surg 188:483-490

5. Lynch AC, Delaney CP, Senagore AJ et al. (2004) Clinical outcome and factors predictive of recurrence after enterocutaneous fistula surgery. Ann Surg 240:825-831

6. Scripcariu V, Carlson G, Bancewicz J et al. (1994) Reconstructive abdominal operations after laparostomy and multiple repeat laparotomies for severe intra-abdominal infection. $\mathrm{Br} \mathrm{J}$ Surg 81:1475-1478

7. Sitges-Serra A, Jaurrieta E, Sitges-Creus A (1982) Management of postoperative enterocutaneous fistulas: the roles of parenteral nutrition and surgery. Br J Surg 69:147-150

8. Conter RL, Roof L, Roslyn JJ (1988) Delayed reconstructive surgery for complex enterocutaneous fistulae. Am Surg 54:589_ 593

9. Levy E, Frileux P, Cugnenc PH et al. (1989) High-output external fistulae of the small bowel: management with continuous enteral nutrition. Br J Surg 76:676-679

10. Schein M, Decker GA (1991) Postoperative external alimentary tract fistulas. Am J Surg 161:435-438

11. Chamberlain RS, Kaufman HL, Danforth DN (1998) Enterocutaneous fistula in cancer patients: etiology, management, outcome, and impact on further treatment. Am Surg 64:12041211 
12. Hollington P, Mawdsley J, Lim W et al. (2004) An 11-year experience of enterocutaneous fistula. Br J Surg 91:1646-1651

13. Reber HA, Roberts C, Way LW et al. (1978) Management of external gastrointestinal fistulas. Ann Surg 188:460-467

14. Campos AC, Meguid MM, Coelho JC (1996) Factors influencing outcome in patients with gastrointestinal fistula. Surg Clin North Am 76:1191-1198

15. Tassiopoulos AK, Baum G, Halverson JD (1996) Small bowel fistulas. Surg Clin North Am 76:1175-1181

16. Makhdoom ZA, Komar MJ, Still CD (2000) Nutrition and enterocutaneous fistulas. J Clin Gastroenterol 31:195-204

17. Evenson AR, Fischer JE (2006) Current management of enterocutaneous fistula. J Gastrointest Surg 10:455-464

18. Schein M, Decker GA (1990) Gastrointestinal fistulas associated with large abdominal wall defects: experience with 43 patients. Br J Surg 77:97-100

19. Carlson GL (2003) Surgical management of intestinal failure. Proc Nutr Soc 62:711-718

20. Lloyd DA, Gabe SM, Windsor AC (2006) Nutrition and management of enterocutaneous fistula. Br J Surg 93:1045-1055

21. Rinsema W. (1992) Thesis: Gastro-intestinal Fistulas, Management and Results of Treatment. Department of Surgery. Maastricht: Maastricht University, p 175

22. Gerzof SG, Robbins AH, Johnson WC et al. (1981) Percutaneous catheter drainage of abdominal abscesses: a five-year experience. N Engl J Med 305:653-657

23. Johnson WC, Gerzof SG, Robbins AH et al. (1981) Treatment of abdominal abscesses: comparative evaluation of operative drainage versus percutaneous catheter drainage guided by computed tomography or ultrasound. Ann Surg 194:510-520

24. Williams NM, Scott NA, Irving MH (1997) Successful management of external duodenal fistula in a specialized unit. Am J Surg 173:240-241

25. Dudrick SJ, Maharaj AR, McKelvey AA (1999) Artificial nutritional support in patients with gastrointestinal fistulas. World $\mathbf{J}$ Surg 23:570-576
26. Hill GL, Bourchier RG, Witney GB (1988) Surgical and metabolic management of patients with external fistulas of the small intestine associated with Crohn's disease. World J Surg 12:191197

27. Rinsema W, Gouma DJ, von Meyenfeldt MF et al. (1990) Primary conservative management of external small-bowel fistulas. Changing composition of fistula series? Acta Chir Scand $156: 457-462$

28. MacFadyen BV Jr, Dudrick SJ, Ruberg RL (1973) Management of gastrointestinal fistulas with parenteral hyperalimentation. Surgery 74:100-1005

29. Altomare DF, Serio G, Pannarale OC et al. (1990) Prediction of mortality by logistic regression analysis in patients with postoperative enterocutaneous fistulae. Br J Surg 77:450-453

30. Reinhardt GF, Myscofski JW, Wilkens DB et al. (1980) Incidence and mortality of hypoalbuminemic patients in hospitalized veterans. JPEN J Parenteral Enteral Nutr 4:357-359

31. Gibbs J, Cull W, Henderson W et al. (1999) Preoperative serum albumin level as a predictor of operative mortality and morbidity: results from the National VA Surgical Risk Study. Arch Surg 134:36-42

32. Kuvshinoff BW, Brodish RJ, McFadden DW et al. (1993) Serum transferrin as a prognostic indicator of spontaneous closure and mortality in gastrointestinal cutaneous fistulas. Ann Surg 217:615-22; discussion 622-623

33. Rosenthal RA (2004) Nutritional concerns in the older surgical patient. J Am Coll Surg 199:785-791

34. Jernigan TW, Fabian TC, Croce MA et al. (2003) Staged management of giant abdominal wall defects: acute and long-term results. Ann Surg 238:349-55; discussion 355-357

35. Sriussadaporn S, Sriussadaporn S, Kritayakirana K et al. (2006) Operative management of small bowel fistulae associated with open abdomen. Asian J Surg 29:1-7 